\title{
PENGEMBANGAN BAHAN AJAR KOMIK SISWA DI KELAS 3 PADA TEMA 2 DI SDN TLOGI BLITAR
}

\author{
Aghitsatul Habibah ${ }^{1}$, Arina Restian ${ }^{2}$, Murtyas Galuh Danawati ${ }^{3}$, Alfiani Athma Putri \\ Rosyadi $^{3}$ \\ Pendidikan Guru Sekolah Dasar, Universitas Muhammadiyah Malang 1,2,3 \\ Pendidikan Matematika, Universitas Muhammadiyah Malang ${ }^{4}$ \\ Email: alfi_rosyadi@umm.ac.id
}

\begin{abstract}
Abstrak
Tujuan penelitian ini adalah mendeskripsikan hasil pengembangan bahan ajar komik Sahabat untuk siswa kelas 3 di SDN Tlogo 02 Blitar. Penelitian pengembangan ini menggunakan model ADDIE. Model pengembangan ADDIE terdiri dari lima tahapan yaitu Analisis, Desain, Pengembangan, Implementasi, dan Evaluasi. Teknik analisis data yang digunakan yakni teknik analisis data kualitatif dan teknik analisis data kuantitatif dengan tujuan untuk mengetahui bagaimana pengembangan kelayakan bahan ajar E-Comic siswa di kelas 3 pada tema 2 SDN Tlogo 02 Blitar. Pada analisis, peneliti melakukan pengkajian teori dan materi, pada tahap desain peneliti menyusun komik Sahabat, pada tahap pengembangan dan implementasi peneliti menerapkan hasil komik yang sudah disusun, pada tahap evaluasi, peneliti melakukan refleksi dari hasil yang sudah diperoleh setelah penerapan komik. Bahan ajar komik Sahabat untuk siswa kelas 3 SDN Tlogo 02 mendapatkan presentase nilai validasi materi pembelajaran 81.8 layak sesuai revisi. Validasi bahan ajar $91.6 \%$ dengan kualifikasi layak tanpa revisi, respon siswa pada komik Sahabat mendapatkan presentase sebesar $99.5 \%$ yang menunjukkan bahwa komik Sahabat sangat layak.
\end{abstract}

Kata Kunci : Pengembangan, Comic, Model ADDIE

\begin{abstract}
The purpose of this study was to describe the results of developing Sahabat comics teaching materials for grade 3 students at SDN Tlogo 02 Blitar. This development research uses the ADDIE model. The ADDIE development model consists of five stages, namely Analysis, Design, Development, Implementation, and Evaluation. The data analysis techniques were qualitative data analysis techniques and quantitative data analysis techniques with the aim of knowing how to develop the feasibility of E-Comic teaching materials for students in grade 3 on theme 2 SDN Tlogo 02 Blitar. In the analysis, the researcher conducted an assessment of theory and material, at the design stage the researcher compiled Sahabat comic, at the development and implementation stage the researcher applied the comic results that had been compiled, at the evaluation stage, the researcher reflected on the results that had been obtained after the application of the comic. Sahabat comic teaching materials for grade 3 students of SDN Tlogo 02 get a percentage value of 81.8 valid learning materials according to revision. Validation of teaching materials is $91.6 \%$ with proper qualifications without revision, student responsed to Sahabat comics get a percentage of $99.5 \%$ indicating that Sahabat comics is very worth it.
\end{abstract}

Key Words : Development, Comic, ADDIE Model

\section{PENDAHULUAN}

Pembelajaran merupakan kegiatan menyampaikan pengetahuan, keterampilan, dan sikap dari guru kepada siswa ([1]-[4]). Pembelajaran merupakan interaksi guru terhadap siswa-siswanya ([5],[6]). Pembelajaran adalah proses interaksi yang dilakukan diantara siswa dengan guru dalam sebuah lingkungan belajar [7].
Berdasarkan hasil wawancara awal pada tanggal 18 Januari 2021 di SD Tlogo 2, sekolah ini merupakan salah satu sekolah yang sudah menerapkan sistem pembelajaran dalam daring selama pandemi Covid-19 ini. Kepala Sekolah juga memaparkan bahwa meskipun pembelajaran dalam jaringan, sekolah mengupayakan fasilitas untuk siswa harus 
dipenuhi. Sehingga selain menyiapkan perangkat pembelajaran, seorang guru harus mampu mengembangkan bahan ajar agar apa yang disampaikan kepada siswa sesuai dengan kemampuan dan kebutuhan kondisi siswa yang diajarnya ([1], [8]).

Ada macam-macam jenis dari bahan ajar yang digunakan di sekolah antara lain yaitu bahan ajar audio, visual dan audio visual ([9]-[11]). Komik adalah salah satu contoh bahan ajar visual yang dapat digunakan oleh siswa. Penelitian tentang komik sudah dilakukan oleh untuk meningkatkan motivasi dan hasil belajar siswa ([5], [11][13]).

Selama pandemic covid 19 ini motivasi belajar siswa menjadi menurun ([14][16]). Oleh karena itu diperlukan media pembelajaran yang dapat meningkatkan motivasi belajar siswa. Komik dapat digunakan untuk meningkatkan motivasi belajar siswa selama pembelajaran ([2], [3], [17]-[19], [4]-[6], [8], [12], [14][16]).

Berdasarkan hasil paparan latar belakang diatas, maka diperlukan adanya kajian dengan topik "Pengembangan Bahan Ajar komik Siswa di kelas 3 pada Tema 2 SDN Tlogo 02 Blitar" dengan tujuan dapat membantu guru kelas 3 dalam proses dari pembelajaran di dalam kelas online.

Penelitian tentang pengembangan bahan ajar komik sudah dilakukan oleh ([11], [13], [20], [21]), tetapi berdasarkan hasil kajian peneliti belum ada yang menggunakan pembelajaran berbasis online saat menerapkan di kelas. Hal ini yang menjadikan peneliti mengembangkan Bahan Ajar komik Siswa di kelas 3 pada Tema 2 SDN Tlogo 02 Blitar.

\section{METODE}

Penelitian ini termasuk ke dalam jenis metode penelitian dan pengembangan $\mathrm{R} \&$
D (Research and Development). Model penelitian ini merupakan model penelitian yang telah memperoleh suatu produk tertentu serta melakukan pengujian keefektifan suatu produk yang telah dihasilkan. Produk yang dihasilkan bukan hanya efektif digunakan tetapi juga sesuai dengan kebutuhan di lapangan. Hal inilah yang menjadi alasan pemilihan model ADDIE dalam upaya pengembangan Komik serta dengan menerapkan suatu model ADDIE memudahkan untuk melakukan sebuah pengembangan yang menghasilkan sebuah produk berupa media pembelajaran.

Penelitian pengembangan Komik ini menggunakan model pengembangan ADDIE. Model pengembangan ADDIE terdadap 5 tahapan yaitu analysis, design, development, implementation, dan evaluation [22]. Adapun proses penelitian dari pengembangan ADDIE di dalam penelitian ini jika diberikan dalam bentuk Gambar 1 sebagai berikut:

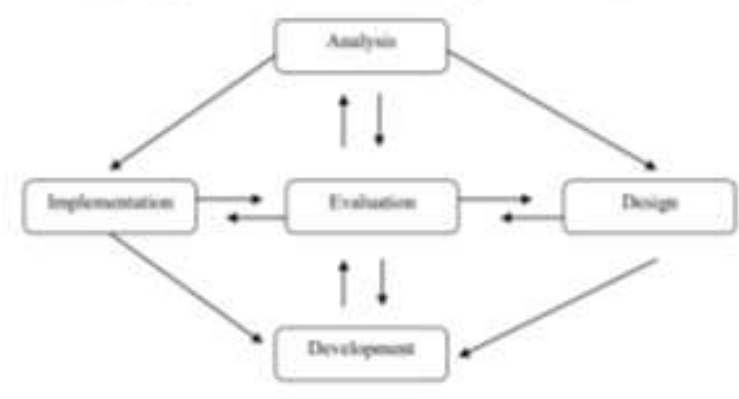

Gambar 1. Model ADDIE

Penelitian pengembangan ini dilaksanakan di semester genap tahun ajaran 2021 di SDN Tlogo 2. Produk yang dikembangkan diujikan dengan melibatkan 2 validator, yakni validasi ahli bahan ajar dan validasi ahli materi.

Teknik pengumpulan data yang dilaksanakan saat penelitian yaitu wawancara, observasi, angket, dan dokumentasi. Wawancara dilakukan oleh 
peneliti kepada guru SDN Tlogo 2 serta wawancara dengan beberapa peserta didik kelas 3. Observasi dilakukan di SDN Tlogo 2, Kegiatan ini merupakan proses kegiatan pembelajaran dengan melihat interaksi antara guru dengan siswa, dan sarana prasarana dalam pembelajaran. Angket digunakan untuk melakukan pengumpulkan data yang diperlukan oleh peneliti berupa angket validasi dan angket respon guru serta angket kepada siswa mengenai modul yang dikembangkan. Dokumentasi selama penelitian dilakukan pada saat melakukan observasi awal sampai implementasi penggunaan komik. Kegiatan ini dipergunakan untuk melakukan pengumpulan data yang berupa gambar, foto, dokumen tertulis untuk mengembangkan komik sahabat

\section{HASIL DAN PEMBAHASAN}

Produk yang dikembangkan dalam penelitian ini adalah berupa Komik Sahabat. Produk ini dirancang dengan memuat pembelajaran tematik PPKn, Bahasa Indonesia dan PJOK. Bahan Ajar komik Tematik tidak dicetak dengan bentuk seperti buku melainkan dalam bentuk software, Aplikasi yang digunakan adalah Adobe Ilustrator CC 2017 dan Adobe Photoshop CC 2017, Jenis dan ukuran huruf pada bagian Cover Badaboom adalah 14, 15, 24, 36 pt. Sedangkan pada bagian Backcover MyriadPro adalah 16 pt, jenis huruf action man.

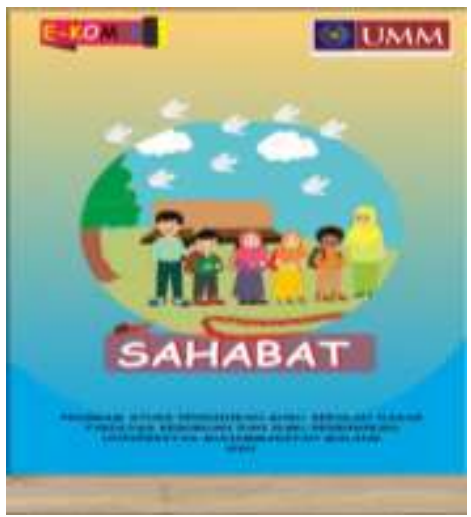

Gambar 2. Cover Komik
Berdasarkan hasil validasi yang dilakukan oleh ahli dan hasil pembagian angket respon siswa memperoleh hasil sebagai berikut :

1. Hasil validasi yang dilakukan oleh ahli materi $81.8 \% \rightarrow$ Layak sesuai revisi

2. Hasil validasi ahli bahan ajar $91.6 \% \rightarrow$ Layak tanpa revisi

3. Hasil respon siswa rata rata di atas 99.5\% $\rightarrow$ Sangat Layak

Berikut ini merupakan tabel rekapan untuk hasil validasi materi

\section{Tabel 1. Analisis Validasi Ahli Materi}

\begin{tabular}{clc}
\hline No & Aspek yang dinilai & Nilai \\
\hline 1. & $\begin{array}{l}\text { Materi tema yang ke- 2 dan } \\
\text { subtema 2 pembelajaran 2 sudah } \\
\text { sesuai dengan standar kompetensi }\end{array}$ & 3 \\
2. & $\begin{array}{l}\text { Materi tema 2 subtema 2 } \\
\text { pembelajaran ke-2 sudah } \\
\text { disesuaikan kompetensi dasar }\end{array}$ & 3 \\
3. & $\begin{array}{l}\text { Materi sesuai dengan tujuan dan } \\
\text { manfaat }\end{array}$ & 4 \\
4. & $\begin{array}{l}\text { Materi sesuai dengan tujuan dan } \\
\text { manfaat }\end{array}$ & 3
\end{tabular}

5. Isi materi yang disajikan sesuai dengan standar kompetensi

6. Isi materi yang disajikan sesuai 3 dengan kompetensi dasar

7. Bahasa dalam materi mudah 3 dipahami siswa

8. Bahasa dalam materi mudah 4 dipahami siswa

9. Penulisan kosakata materi ditulis 3 dengan benar

10. Penulisan kosakata materi ditulis 3 dengan benar

11. Penggunaan bahan ajar 4 mempermudah pemahaman siswa Total

Nilai Per Item

Pembelajaran dari tematik yang diajarkan kepada siswa dipergunakan untuk tidak berfikir secara kognitif saja melainkan juga mengembangkan aspek kognitif, afektif serta psikomotorik. Sebagian besar siswa sekolah dasar belum dapat mengaitkan 
antara pengetahuan prasyarat yang sudah diperoleh dengan menerapkan hasil dari pengetahuan ini ([13], [21]). Dalam penelitian pengembangan bahan ajar ecomic sahabat, produk media yang peneliti kembangkan telah berhasil dikembangkan melalui 5 tahapan model penelitian ADDIE yaitu Analysis, Design, Development, Implementation dan Evaluation ([22], [23]).

Berikut adalah penjelasan setiap tahap penelitian yang sudah peneliti lakukan dalam pengembangan bahan ajar e_comic sahabat. Tahap yang pertama adalah tahap analisis, tahap analisis bertujuan untuk mengetahui kondisi nyata dilapangan dan mengumpulkan informasi sebanyak banyaknya terhadap permasalahan permasalahan yang dialami siswa kelas 3 SDN Tlogo 02. Dalam tahap ini peneliti melakukan observasi dan wawancara kepada 66 guru wali kelas 3 dan beberapa siswa kelas 3 SDN Tlogo 02.

Dari permasalahan permasalahan yang peneliti temukan, peneliti melakukan analisis dengan menghasilkan analisa kebutuhan, analisa kurikulum dan analisa karakteristik siswa. Berdasarkan hasil dari wawancara dan kegiatan observasi yang sudah dilaksanakan dengan menggunakan bahan ajar yang digunakan berupa buku paket. Berdasarkan kondisi tersebut, diperlukan adanya pengembangan bahan ajarsebagai penunjang serta memudahkan siswa dalam melaksanakan pembelajaran khususnya dalam pembelajaran tematik. Hal tersebut sesuai dengan hasil dari penelitian yang menyatakan bahan ajar ekomik sangat efektif digunakan sebagai pembelajaran [21].

Bersumber dari data di atas salah satu media yang dikembangkan dalam pembelajaran adalah e-komik. Tahap yang kedua adalah tahap desain, tahap desain bertujuan untuk membuat rancangan produk yang sesuai dengan analisa kebutuhan siswa kelas 3 di SDN Tlogo 2 . Berdasarkan analisa kebutuhan yang peneliti peroleh, bahwa siswa kelas 3 di SDN Tlogo 02 membutuhkan bahan ajar yang menarik dan bergambar untuk mendukung pembelajaran daring. Hal ini selaras dengan pendapat bahwa bahan ajar adalah berbagai macam benda yang dirancang dengan sistematis yang dapat menyampaikan informasi yang dapat dipahami dengan baik oleh peserta didik [23]. Bahan ajar digunakan di dalam kegiatan pembelajaran dan dirumuskan sesuai dengan tujuan perencanaan pelaksanaan pembelajaran, seperti buku, modul, LKPD dan sebagainya. Maka dari itu peneliti membuat rancangan produk bahan ajar e-comic sahabat.

Berdasarkan hasil kerja dari suatu bahan ajar, bisa dikategorikan menjadi lima bentuk antara lain yaitu: bahan ajar yang tidak bisa diproyeksikan, artinya bahwa bahan ajar itu langsung dapat digunakan dengan cara dilihat, diamati dan dibaca oleh siswa ([10], [23]). Contoh dari bahan ajar yang tidak bisa diproyeksikan yaitu buku, modul, LKS, gambar dll. Selanjutnya yaitu bahan ajar yang perlu diproyeksikan misalkan adalah slide power point, filmstrip dll. Hal ini berarti bahwa diperlukan proyektor atau benda lain agar bahan ajar tadi dapat dimanfaatkan oleh siswa. Bahan ajar berikutnya adalah audio yaitu bahan ajar yang memerlukan benda untuk merekam, sebagai contoh $\mathrm{CD}$, tape, flashdisk dsb. Contoh bahan ajarnya kaset, Compact Disk, dan sebagainya. Untuk berikutnya yaitu bahan ajar video yakni bahan ajar yang sebelum digunakan memerlukan alat bantu untuk memutar video yaitu $D V D$ player, video tape player, $V C D$ player, dan lain lain. Bahan ajar yang digunakan ini dapat menampilkan suara serta gambar secara bersama-sama. Contoh dari bahan ajar ini adalahvideo, film, dll. Yang terakhir yaitu bahan ajar yang 
berbantuan computer, yaitu bahan ajar bukan cetak yang dalam menerapkannya menggunakan PC untuk menyajikan suatu hal untuk digunakan. Misalnya adalah computer mediated instruction, dan juga computer based multimedia.

Tahap yang ketiga adalah Development atau pengembangan, pada tahap ini merupakan proses pembuatan media yang telah dirancang menjadi bentuk nyata. Untuk menguji kelayakan bahan ajar maka perlu adanya validasi ahli materi pembelajaran dan bahan ajar untuk mengetahui tingkat kelayakan dan sebagai evaluasi agar produk e-comic Sahabat yang peneliti kembangkan dapat lebih baik. Berikut adalah hasil validasi materi dan bahan ajar. Dalam hasil akhir $81.8 \%$ dari ahli materi dengan saran untuk menambahkan materi khsusus Bahasa Indonesia dan dari ahli bahan ajar pembelajaran tematik mendapatkan nilai 91.6\% dengan saran untuk lebih mengoptimalkan face setiap tokoh yang ada di dalam e-comic sahabat. Berdasarkan hasil validasi ahli materi dan bahan ajar dapat digunakan untuk pembelajaran di SDN Tlogo 02 karena memperoleh hasil layak atau valid. 68 Hal ini didukung dengan pendapat bahwa bahan ajar adalah seperangkat yang berisi materi dan disusun terstruktur sehingga terciptanya sebuah lingkungan yang memungkinkan bagi siswa untuk belajar dengan baik dan benar [20].

Tahap ke empat adalah implementasi, pada tahap ini bertujuan untuk uji coba produk bahan ajar e-comic sahabat di SDN Tlogo 02. Sebelum melakukan pembelajaran menggunakan produk bahan ajar e-comic sahabat, peneliti melakukan implementasi kepada siswa dengan kelas daring yang diikuti oleh 20 siswa. Setelah pembelajaran selesai peneliti membagikan angket respon siswa guna untuk mengetahui respon pengguna terhadap produk bahan ajar e- comic sahabat. Dibuktikan dengan pendapat bahwa bahan ajar yang diberikan bisa memunculkan semangat yang bersifat positif. Hal ini dimaksudkan bahwa bahan ajar yang diberikan dapat diatur dan dirancang penggunannya dengan tepat dan sesuai dalam kegiatan pembelajaran [11].

Tahap kelima adalah evaluasi, pada tahap ini bertujuan untuk mengetahui tingkat pemahaman siswa. Evaluasi pengembangan dilakukan dengan dua validasi yakni validasi materi dan validasi media oleh para validator media dan materi dengan tujuan hasil validasi digunakan sebagai data pengukuran yang telah dikembangkan. Berdasarkan hasil angket respon pengguna, maka dijelaskan bahwa siswa kelas tiga SDN Tlogo 02 memberikan penilaian sangat baik terhadap produk bahan ajar e-comic sahabat dengan hasil $99.5 \%$.

Dari data angket respon, dapat diketahui bahwa bahan ajar e-comic sahabat ini membantu siswa untuk lebih mudah belajar hal ini sesuai dengan apa yang disampaikan oleh [10] bahwa bahan ajar sebagai suatu hal mengantarkan informasi serta hal baru pada proses komunikasi antara pendidik dengan siswa. bahan ajar e-comic sahabat didesain untuk membantu guru menyampaikan materi pada tema dua dan subtema dua pada pembelajaran ke 2, dan siswa dapat lebih rajin lagi untuk belajar membaca dan memahami setiap kalimat yang terdapat pada $e$-comic.

\section{SIMPULAN}

Bahan ajar komik Sahabat untuk siswa kelas tiga SDN Tlogo 02 yang sudah dikembangkan bisa membuat motivasi siswa dan dapat mempermudah pemahaman untuk belajar tematik khususnya tema dua subtema dua. Kelayakan bahan ajar komik Sahabat ditinjau dari ahli yaitu ahli validasi materi dan ahli validasi bahan ajar serta respon 
siswa yang memuaskan. adapun saransaran yang dapat peneliti sampaikan yang berhubungan dengan penelitian pengembangan ini sebagai berikut : Guru dapat menggunakan bahan ajar komik Sahabat untuk memberikan submateri yang ada di tematik tema dua subtema dua kelas 3 sehingga dapat membantu guru untuk meningkatkan hasil belajar, dan dapat membuat siswa lebih rajin membaca, dan Siswa dapat dengan mudah memahami materi, termotivasi untuk belajar serta membantu peserta didik dalam pembelajaran tematik tema dua subtema dua serta siswa dapat lebih termotivasi untuk belajar membaca lebih lancar

\section{DAFTAR PUSTAKA}

[1] A. Buchori and R. D. Setyawati, "Development Model of Charactereducation Through Ecomic in Elementary School. International Journal of Education and Research," Int. J. Educ. Res., vol. 3, no. 9, 2015.

[2] A. Z. Fayruza and A. B. P. Yodhi, "Literasi Pembelajaran Bahasa Arab Melalui Media Pembelajaran Komik untuk Siswa Tingkat SD/MI," Inov. Media Pembelajaran Bahasa, Sastra, dan Budaya Arab, vol. 2, no. 1, 2018.

[3] E. S. Syarah, E. Yetti, L. Fridani, Yufiarti, Hapidin, and B. Pupala, "Electronic comics in elementary school science learning for marine conservation," J. Pendidik. IPA Indones., vol. 8, no. 4, 2019, doi: 10.15294/jpii.v8i4.19377.

[4] L. Mustikasari, G. Priscylio, T. Hartati, and W. Sopandi, "The Development of Digital Comic on Ecosystem for Thematic Learning in Elementary Schools," in Journal of Physics: Conference Series, 2020, vol. 1469 , no. 1, doi: 10.1088/17426596/1469/1/012066.

[5] N. Maulidah and F. Wulandari,
"Literature Study: Improving Understanding of Science Concepts Using Science Comics for Elementary School Students," $J$. Penelit. Pendidik. IPA, vol. 7, no. 1, 2021, doi: 10.29303/jppipa.v7i1.509.

[6] N. Hermita et al., "Developing Science Comics for Elementary School Students on Animal Diversity," Solid Sci. Technol., vol. 63, no. 1s, 2020.

[7] A. K. Ellis and J. B. Bond, "Direct Instruction," in Research on Educational Innovations, 2018.

[8] H.-Y. Phoon, R. Roslan, M. Shahrill, and H. M. Said, "The Role of Comics in Elementary School Science Education," J. Ilm. Pendidik. $M I P A$, vol. 10, no. 2, 2020.

[9] E. F. Kurniawati, "Pengimplementasian E-modul Etnokonstruktivisme terhadap Motivasi Belajar Peserta Didik Kelas V sekolah dasar," J. Penelit. Ilmu Pendidik., vol. 13, no. 1, 2020, doi: 10.21831/jpipfip.v13i1.26589.

[10] N. A. Pandanwangi, F. Kristin, and I. Anugraheni, "Pengembangan Media Komik untuk Meningkatkan Kompetensi Berbahasa pada Siswa Kelas 3 SD," J. Cakrawala Pendas, vol. 5, no. 2, 2019, doi: 10.31949/jcp.v5i2.1354.

[11] L. Fahrunnisa, A. A. Adiansha, A. Irawan, A. Amrin, and Z. Zulharman, "Pendekatan Etnomatematika: Bagaimana Pengembangan Media Komik dalam Pemecahan Masalah pada Pembelajaran Matematika SD?," JagoMIPA J. Pendidik. Mat. dan IPA, vol. 1, no. 1, 2021, doi: 10.53299/jagomipa.v1i1.33.

[12] E. E. Subekti and D. F. Istiyanti, "Komik Bilangan Romawi untuk Meningkatkan Hasil Belajar Matematika Siswa Kelas IV SD," Malih Peddas (Majalah Ilm. Pendidik. Dasar), vol. 6, no. 2, 2017, 
doi:

10.26877/malihpeddas.v6i2.1347.

[13] I. Mujahadah, A. Alman, and M. Triono, "Pengembangan Media Pembelajaran Komik untuk Meningkatkan Hasil dan Minat Belajar Matematika Peserta Didik Kelas III SD Muhammadiyah Malawili," J. Papeda J. Publ. Pendidik. Dasar, vol. 3, no. 1, 2021, doi:

10.36232/jurnalpendidikandasar.v3i1 .758 .

[14] R. H. Syah, "Dampak Covid-19 pada Pendidikan di Indonesia: Sekolah, Keterampilan, dan Proses Pembelajaran," SALAM J. Sos. dan Budaya Syar-i, vol. 7, no. 5, 2020, doi: $10.15408 /$ sjsbs.v7i5.15314.

[15] A. Latip, "Peran Literasi Teknologi Informasi dan Komunikasi pada Pembelajaran Jarak Jauh di Masa Pandemi Covid-19," EduTeach J. Edukasi dan Teknol. Pembelajaran, vol. 1, no. 2, 2020, doi: 10.37859/eduteach.v1i2.1956.

[16] L. D. Herliandry, N. Nurhasanah, M. E. Suban, and H. Kuswanto, "Pembelajaran pada Masa Pandemi Covid-19," JTP - J. Teknol. Pendidik., vol. 22, no. 1, 2020, doi: 10.21009/jtp.v22i1.15286.

[17] E. Masri, N. P. Wahyuni, and A. M. Rini, "Perilaku Memilih Jajanan dan Kantin Sehat Siswa Sekolah Dasar dengan Edukasi Media Komik," $J$. Kesehat. PERINTIS (Perintis's Heal. Journal), vol. 6, no. 2, 2019, doi: 10.33653/jkp.v6i2.278.

[18] R. F. Kusumadewi, A. Neolaka, and M. Yasin, "Improving the Ability of Understanding Mathematical Concepts Through Digital-based Comics for Elementary School Students," Al Ibtida J. Pendidik. Guru MI, vol. 7, no. 2, 2020, doi: 10.24235/al.ibtida.snj.v7i2.7024.

[19] Y. Sari, R. P. Sari, M. S. Sumantri, and A. Marini, "Development of Digital Comic for Science Learning in Elementary School," IOP Conf. Ser. Mater. Sci. Eng., vol. 1098, no. 3 , 2021, doi: 10.1088/1757899x/1098/3/032060.

[20] F. Muliani, "Pembangan Media Pembelajaran Berupa Buku Komik pada Materi Sejarah di Sekolah Dasar (Studi Kasus: SD Negeri 148 Pekanbaru)," EduTeach J. Edukasi dan Teknol. Pembelajaran, vol. 1, no. $1, \quad 2020, \quad$ doi: 10.37859/eduteach.v1i1.1806.

[21] A. G. Wicaksono, J. Jumanto, and O. Irmade, "Pengembangan Media Komik Komsa Materi Rangka pada Pembelajaran IPA di Sekolah Dasar," Prem. Educ. J. Pendidik. Dasar dan Pembelajaran, vol. 10, no. 2, 2020, doi: 10.25273/pe.v10i2.6384.

[22] S. Kurt, "ADDIE Model: Instructional Design," Frameworks \& Theories, 2017. .

[23] T. D. Kurnia, C. Lati, H. Fauziah, and A. Trihanton, "Model ADDIE untuk Pengembangan Bahan Ajar Berbasis Kemampuan Pemecahan Masalah Berbantuan 3D," Semin. Nas. Pendidik. Mat., vol. 1, no. 1, 2019. 